\title{
The Risk of Newly Diagnosed Cancer in Patients with Rheumatoid Arthritis by TNF Inhibitor Use: A Nationwide Cohort Study
}

\section{Boyoon Choi}

Seoul National University College of Pharmacy

Hyun Jin Park

Seoul National University College of Pharmacy

\section{Yun-Kyoung Song}

Daegu Gatollik Daehakkyo: Catholic University of Daegu

\section{Yoon-Jeong Oh}

Kangwon National University College of Medicine: Kangwon National University School of Medicine

\section{In-Wha Kim}

Seoul National University College of Pharmacy

Jung Mi Oh ( $\square$ jmoh@snu.ac.kr)

Seoul National University College of Pharmacy https://orcid.org/0000-0002-1836-1707

\section{Research article}

Keywords: Arthritis, rheumatoid, Biological products, Cohort studies, Drug-related side effects and adverse reactions, Neoplasms, Tumor necrosis factor inhibitors

Posted Date: October 26th, 2021

DOl: https://doi.org/10.21203/rs.3.rs-998749/v1

License: @ (i) This work is licensed under a Creative Commons Attribution 4.0 International License. Read Full License 


\section{Abstract \\ Background}

Tumor necrosis factor (TNF) inhibitors use in patients with rheumatoid arthritis (RA) has raised safety concerns about cancer risk, but study results remain controversial. This largest nationwide study to date compared cancer risk in TNF inhibitor users to non-biologic disease-modifying anti-rheumatic drug (nbDMARD) users in Korean patients with RA.

\section{Methods}

Data on all the eligible patients diagnosed with RA between 2005 and 2016 were retrieved from the Korean National Health Information Database. The one-to-one matched patients consisted of the matched cohort. The risks for developing all-type and site-specific cancers were estimated using incidence and incidence rate (IR) per 1,000 person-years. Adjusted hazard ratio (HR) and 95\% confidence interval $(\mathrm{Cl})$ were estimated using a Cox regression model.

\section{Results}

Of the 22,851 patients in the before matching cohort, 4,592 patients were included in the matched cohort. Treatment with TNF inhibitors was consistently associated with a lower risk of cancer than in the nbDMARD cohort (IR per 1,000 person-years, 6.5 vs. 15.6; adjusted $\mathrm{HR}, 0.379 ; 95 \% \mathrm{Cl}, 0.255-0.563$ ). The adjusted $\mathrm{HR}(95 \% \mathrm{Cl})$ was significantly lower in the TNF inhibitor cohort than the nbDMARD cohort for gastrointestinal cancer $(0.432 ; 0.235-0.797)$, breast cancer $(0.146 ; 0.045-0.474)$, and genitourinary cancer $(0.220 ; 0.059-0.820)$.

\section{Conclusions}

The use of TNF inhibitors was associated with a lower cancer incidence in Korean patients with RA. A further study linking claims and clinical data is needed to confirm our results.

\section{Background}

Rheumatoid arthritis (RA) is a systemic autoimmune disease that leads to major comorbidities and mortality [1]. Because of the autoimmune pathogenesis of RA and the common etiology for RA and malignancy, RA has been suggested to increase the risk of cancer [2]. Elevated RA disease activity and complications have also been associated with an increased risk of cancer $[3,4]$. Furthermore, the conventional treatment for RA, non-biologic disease-modifying anti-rheumatic drugs (nbDMARDs) such as methotrexate, was reported to accelerate cancer development by altering normal immunosurveillance [5]. 
Recently, biologic DMARDs, including tumor necrosis factor (TNF) inhibitors such as adalimumab, etanercept, infliximab, and golimumab, have been developed and enabled more effective disease control [6]. However, the introduction of TNF inhibitors has raised safety concerns about the risk of cancer. Although TNF-a is a proinflammatory cytokine involved in chronic inflammation in RA and the development and progression of cancer [7-9], it also plays an essential role in combating infection and killing tumor cells through natural killer cells and CD8 lymphocytes [10-12]. Therefore, treatment with TNF inhibitors could impair immunity and thereby increase the potential risk of infection and cancer.

Under this background, the results of previous studies on the risk of cancer in patients with RA treated with TNF inhibitors are controversial [1], [13-18]. Bongartz et al. reported a significantly higher incidence of cancer, but Wu et al. reported decreased cancer risk with TNF inhibitor treatment [1], [15]. For sitespecific cancer, Raaschou et al. and Hellgren et al. reported nearly double the risk for squamous cell cancer and lymphoma [19,20], while other studies found no association between those types of cancer and treatment with TNF inhibitors [21, 22].

This nationwide cohort study assessed the risk of all-type and site-specific cancers in Korean patients with RA treated with TNF inhibitors and compared them to those treated with nbDMARDs, using a national administrative database.

\section{Methods}

In this study, we used data from the National Health Insurance Service-National Health Information Database (NHIS-NHID) [23], which is a longitudinal database containing the health care records and claims data of approximately 50 million national insurance subscribers covering over $96.3 \%$ of the population in South Korea [24]. This study was approved by the institutional review board of the Seoul National University Hospital (No. 1710-112-897).

\section{Study Population}

We used a previously developed and validated algorithm for the NHIS-NHID [25] to retrieve data from 2002 to 2016 on all patients with all M05* RA diagnostic codes of the International Classification of Diseases (ICD)-10, and a prescription of biologic DMARDs (TNF inhibitors and non-TNF biologics, including abatacept, rituximab, tocilizumab, and tofacitinib) or nbDMARDs (auranofin, azathioprine, bucillamine, cyclophosphamide, cyclosporine, D-penicillamine, hydroxychloroquine, leflunomide, methotrexate, minocycline, mizoribine, sulfasalazine, tacrolimus, and mycophenolate mofetil). We excluded patients receiving Medical Aid benefits, with a history of RA or cancer during at least three years before the index date, aged under 19 years, and those using non-TNF biologics. Patients prescribed TNF inhibitors or nbDMARDs for less than six months and those with poor TNF inhibitors compliance, defined as the proportion of days covered (PDC) under 0.8 , were excluded as well. The eligible patients constituted the before-matching cohort, representing the entire study population. The matched cohort was created by matching 1:1 TNF inhibitor users with nbDMARD users to achieve a more controlled 
analysis (Figure 1). The groups were matched for age, sex, comorbidities, the Charlson comorbidity index score, and the start year of nbDMARD treatment.

Under the NHIS program, TNF inhibitor prescription is allowed only to those patients fulfilling the RA diagnostic criteria of the American College of Rheumatology (ACR) and the European League Against Rheumatism (EULAR) [26], with over 5.1 points on the disease activity score 28-joint assessment (DAS28), or 3.2-5.1 points and articular damage on radiographs, who failed to respond to at least six months of treatment with two or more nbDMARDs. According to this reimbursement policy and the exclusion criteria, the TNF inhibitor cohort included patients treated with TNF inhibitors for at least six months and nbDMARDs for at least six months before that. Subjects in the nbDMARDs cohort used only nbDMARDs for at least six months without using any biologic DMARDs.

\section{Follow-up}

The patients were followed up from the index date to 31 December 2016 or the event date, whichever came first. Any loss to follow-up was censored. The index date of TNF inhibitor users was defined as the first date of TNF inhibitors prescription. The nbDMARD users were followed up from the index date of their matched TNF inhibitor users. The nbDMARD users in the before-matching cohort were followed up from the first date of nbDMARDs prescription (Figure 2).

The outcome of interest was a diagnosis of cancer during follow-up. Cancer event was determined as admission to hospital with at least one of the cancer diagnostic codes and treatment codes for chemotherapy, radiotherapy, or surgery [27]. The primary outcome was all-type of cancer (ICD-10 codes $\left.\mathrm{C} 11^{*}-\mathrm{C} 97^{\star}\right)$, and the secondary outcome was site-specific cancers (ICD-10 codes $\mathrm{C} 11^{*}-\mathrm{C} 14^{*}$ for oropharyngeal, $\mathrm{C} 15^{*}-\mathrm{C} 26^{*}$ for gastrointestinal, $\mathrm{C} 15^{*}-\mathrm{C} 16^{*}$ and $\mathrm{C} 170$ for the upper gastrointestinal tract, $\mathrm{C} 18^{*}-\mathrm{C} 20^{*}$ for colorectal, $\mathrm{C} 22^{*}$ for liver, $\mathrm{C} 23^{*}-\mathrm{C} 25^{*}$ for biliary, $\mathrm{C} 3^{*}$ for respiratory, $\mathrm{C} 40^{*}-\mathrm{C} 41^{*}$ for bone and soft tissue, $\mathrm{C} 43^{\star}-\mathrm{C} 44^{*}$ for skin [C43* for melanoma, C44* for non-melanoma], $\mathrm{C} 50^{*}$ for breast, $\mathrm{C} 51^{*}-\mathrm{C} 58^{*}$ for gynecologic, $\mathrm{C} 60^{*}-\mathrm{C} 68^{*}$ for genitourinary, $\mathrm{C} 70^{*}-\mathrm{C} 72^{*}$ for the central nervous system, $\mathrm{C} 73^{*}-\mathrm{C} 75^{*}$ for endocrine, $\mathrm{C} 81^{*}-\mathrm{C} 86^{*}, \mathrm{C} 88^{*}$, and $\mathrm{C} 90^{*}-\mathrm{C} 96^{*}$ for hematologic, and $\mathrm{C} 81^{*}-\mathrm{C} 85^{*}$ and $\mathrm{C} 96^{*}$ for lymphoma). Incident cases within 12 months following the index date were censored.

\section{Confounding Control}

Adjusted confounding variables included age, sex, comorbidities (hypertension, diabetes, dyslipidemia, chronic liver disease, cardiovascular disease, chronic obstructive pulmonary disease, and peptic ulcer disease), the Charlson comorbidity index score [28], disease duration, PDC by nbDMARDs, nonsteroidal anti-inflammatory drugs (NSAIDs), and oral corticosteroids, and income.

Comorbidities and the Charlson comorbidity index score were determined within one year of the index date, following a previously published algorithm [28-33]. Disease duration was defined as the time from the first use of nbDMARDs to the index date. Drug treatments were recorded from the index date to the end of follow-up. The PDC was calculated as the number of days covered by prescription divided by the number of follow-up days for each patient. All other variables were determined as of the index date. 


\section{Statistical Analysis}

Descriptive statistics were used to summarize baseline characteristics and estimate the incidences and incidence rates per 1,000 person-years for cancer. Adjusted hazard ratios (HRs) and $95 \%$ confidence intervals (Cls) were estimated by multivariable analyses using a Cox regression model (or a conditional Cox regression model for the matched cohort). The significance level was set to 0.05 . Subgroup analyses were performed by age, sex, disease duration, type and duration of TNF inhibitor and nbDMARD used, and time to event. We conducted all the analyses using SAS 9.4 software (SAS Institute Inc., Cary, NC, USA).

\section{Sensitivity Analysis and Method Validation}

A lag time of 12 months was assumed in primary analysis for cancer development. We performed a sensitivity analysis by changing this lag time to $0,6,24,36$, and 60 months to assess the robustness of our findings.

We estimated the risk of tuberculosis development as a positive control outcome for method validation since it is well established that the risk of tuberculosis increases with TNF inhibitor use in patients with RA [34]. Subjects with a history of tuberculosis before the index date were excluded from the analysis of tuberculosis risk. The positive control outcome was defined based on tuberculosis ICD-10 diagnostic codes $\mathrm{A} 15^{*}-\mathrm{A} 19^{*}$ and U84* and prescriptions of at least three of the anti-tuberculosis drugs following a previously developed algorithm [35]. A Cox regression model (or conditional Cox regression model for the matched cohort) was used to estimate adjusted HRs and $95 \%$ Cls after adjusting for age, sex, comorbidities (diabetes, chronic liver disease, and chronic obstructive pulmonary disease), the Charlson comorbidity index score, and the start year of nbDMARD use.

\section{Results}

\section{Baseline Characteristics of the Study Cohort}

A total of 62,419 patients with RA were identified in the Korean NHIS-NHID. Of these, we excluded 8,853 Medicaid Aid beneficiaries, 22,745 with RA treatment history, and 1,388 with cancer history during the screening period, 532 younger than 19 years, 2,351 treated with non-TNF biologics, and 3,699 treated with TNF inhibitors or nbDMARDs for less than six months or with poor compliance with TNF inhibitor use. The remaining 22,851 patients constituted the before-matching cohort. Of these, 3,286 were in the TNF inhibitor cohort and 19,565 in the nbDMARD cohort. The groups were then matched 1:1 based on the criteria described in the Methods section, resulting in a matched cohort of 4,592 patients (Figure 1).

The overall baseline characteristics were well balanced in the TNF inhibitor and nbDMARD cohorts, with all matching variables displaying a standardized difference value of less than 0.1 (Table 1). The mean age was $50.3 \pm 13.09$ years, and $78.7 \%$ were female in both cohorts after matching, similar to previous studies on the Korean RA population [13], [36]. 
Table 1

Demographic Characteristics of the Study Cohorts

\begin{tabular}{|c|c|c|c|c|}
\hline \multirow[t]{3}{*}{ Characteristics } & \multicolumn{2}{|c|}{ Before-matching Cohort } & \multicolumn{2}{|c|}{ Matched Cohort } \\
\hline & $\begin{array}{l}\text { TNF Inhibitor } \\
\text { Cohort }\end{array}$ & $\begin{array}{l}\text { nbDMARD } \\
\text { Cohort }\end{array}$ & $\begin{array}{l}\text { TNF Inhibitor } \\
\text { Cohort }\end{array}$ & $\begin{array}{l}\text { nbDMARD } \\
\text { Cohort }\end{array}$ \\
\hline & $(n=3,286)$ & $(n=19,565)$ & $(n=2,296)$ & $(n=2,296)$ \\
\hline Female gender & 2,298 (69.9) & $14,325(73.2)$ & $1,807(78.7)$ & $1,807(78.7)$ \\
\hline Age groups & $50.4 \pm 14.00$ & $57.1 \pm 14.26$ & $50.3 \pm 13.09$ & $50.3 \pm 13.09$ \\
\hline 19 years & $10(0.3)$ & $64(0.3)$ & $6(0.3)$ & $6(0.3)$ \\
\hline 20-29 years & $270(8.2)$ & $797(4.1)$ & $158(6.9)$ & $158(6.9)$ \\
\hline 30-39 years & $516(15.7)$ & $1,587(8.1)$ & $358(15.6)$ & $358(15.6)$ \\
\hline $40-49$ years & $656(20.0)$ & $3,039(15.5)$ & $477(20.8)$ & $477(20.8)$ \\
\hline $50-59$ years & 918 (27.9) & $4,890(25.0)$ & $706(30.7)$ & $706(30.7)$ \\
\hline $60-69$ years & $646(19.7)$ & $5,064(25.9)$ & $443(19.3)$ & $443(19.3)$ \\
\hline 70-79 years & $241(7.3)$ & $3,448(17.6)$ & $138(6.0)$ & $138(6.0)$ \\
\hline $80-89$ years & $28(0.9)$ & $668(3.4)$ & $10(0.4)$ & $10(0.4)$ \\
\hline 90-99 years & $1(0)$ & $8(0)$ & $0(0)$ & $0(0)$ \\
\hline \multicolumn{5}{|l|}{ Comorbidities $^{a}$} \\
\hline Hypertension & $874(26.6)$ & $7,100(36.3)$ & $474(20.6)$ & $474(20.6)$ \\
\hline Diabetes & $324(9.9)$ & $2,662(13.6)$ & $93(4.1)$ & $93(4.1)$ \\
\hline Dyslipidemia & $521(15.9)$ & $3,448(17.6)$ & $221(9.6)$ & $221(9.6)$ \\
\hline CLD & $539(16.4)$ & $2,935(15.0)$ & $208(9.1)$ & $208(9.1)$ \\
\hline CVD & $364(11.1)$ & $4,083(20.9)$ & $128(5.6)$ & $128(5.6)$ \\
\hline COPD & $71(2.2)$ & $808(4.1)$ & $7(0.3)$ & $7(0.3)$ \\
\hline PUD & $503(15.3)$ & $1,982(10.1)$ & $0(0)$ & $0(0)$ \\
\hline \multicolumn{5}{|c|}{ Number of comorbidities ${ }^{a}$} \\
\hline 0 & $1,649(50.2)$ & $8,491(43.4)$ & $1,493(65.0)$ & $1,493(65.0)$ \\
\hline 1 & $959(29.2)$ & $5,043(25.8)$ & $568(24.7)$ & $568(24.7)$ \\
\hline 2 or more & $678(20.6)$ & $6,031(30.8)$ & 235 (10.2) & $235(10.2)$ \\
\hline
\end{tabular}




\begin{tabular}{|c|c|c|c|c|}
\hline \multirow{2}{*}{$\begin{array}{l}\text { Characteristics } \\
1\end{array}$} & \multicolumn{2}{|c|}{ Before-matching Cohort } & \multicolumn{2}{|c|}{ Matched Cohort } \\
\hline & $949(28.9)$ & $5,376(27.5)$ & 775 (33.8) & $833(36.3)$ \\
\hline 2 & $936(28.5)$ & $4,907(25.1)$ & $715(31.1)$ & $656(28.6)$ \\
\hline 3 or more & $1,401(42.6)$ & $9,282(47.4)$ & $806(35.1)$ & $807(35.1)$ \\
\hline Disease duration (months) ${ }^{b}$ & $33.8 \pm 29.79$ & $0 \pm 0$ & $35.6 \pm 30.02$ & $35.6 \pm 30.15$ \\
\hline \multicolumn{5}{|l|}{ TNF inhibitor treatment ${ }^{c}$} \\
\hline Adalimumab user & $1,572(47.8)$ & . & $1,089(47.4)$ & . \\
\hline Etanercept user & $1,270(38.6)$ & . & $882(38.4)$ & . \\
\hline Golimumab user & $401(12.2)$ & . & $285(12.4)$ & . \\
\hline Infliximab user & $673(20.5)$ & . & $474(20.6)$ & . \\
\hline Number of TNF inhibitors & $1.2 \pm 0.45$ & . & $1.2 \pm 0.44$ & \\
\hline $\begin{array}{l}\text { Duration of TNF inhibitors } \\
\text { (months) }\end{array}$ & $37.6 \pm 25.15$ & . & $38.2 \pm 25.23$ & . \\
\hline PDC of TNF inhibitors ${ }^{d}$ & $0.98 \pm 0.043$ & . & $0.98 \pm 0.044$ & . \\
\hline \multicolumn{5}{|l|}{ nbDMARD treatment $^{c}$} \\
\hline Methotrexate user & 2,983 (90.8) & $14,954(76.4)$ & $2,136(93.0)$ & $1,775(77.3)$ \\
\hline Hydroxychloroquine user & 2,539 (77.3) & $16,343(83.5)$ & $1,843(80.3)$ & $1,937(84.4)$ \\
\hline Sulfasalazine user & 2,355 (71.7) & $9,664(49.4)$ & $1,624(70.7)$ & $1,180(51.4)$ \\
\hline Leflunomide user & $1,752(53.3)$ & $7,061(36.1)$ & $1,278(55.7)$ & $884(38.5)$ \\
\hline Number of nbDMARD & $3.6 \pm 1.41$ & $3.1 \pm 1.35$ & $3.7 \pm 1.37$ & $3.3 \pm 1.40$ \\
\hline $\begin{array}{l}\text { Duration of nbDMARD } \\
\text { (months) }\end{array}$ & $37.9 \pm 26.60$ & $49.8 \pm 35.46$ & $39.8 \pm 26.83$ & $35.4 \pm 26.71$ \\
\hline PDC of nbDMARD ${ }^{d}$ & $0.85 \pm 0.312$ & $0.73 \pm 0.303$ & $0.88 \pm 0.288$ & $0.82 \pm 0.328$ \\
\hline \multicolumn{5}{|l|}{$\begin{array}{l}\text { Anti-inflammatory } \\
\text { treatment }^{\mathrm{C}}\end{array}$} \\
\hline PDC of oral corticosteroids ${ }^{d}$ & $0.73 \pm 0.360$ & $0.58 \pm 0.355$ & $0.75 \pm 0.351$ & $0.68 \pm 0.383$ \\
\hline PDC of NSAIDs ${ }^{d}$ & $0.85 \pm 0.262$ & $0.64 \pm 0.340$ & $0.86 \pm 0.255$ & $0.74 \pm 0.348$ \\
\hline \multicolumn{5}{|l|}{ Type of institution } \\
\hline Tertiary hospital & 3,019 (91.9) & $13,180(67.4)$ & $2,114(92.1)$ & $1,556(67.8)$ \\
\hline
\end{tabular}




\begin{tabular}{|c|c|c|c|c|}
\hline \multirow{2}{*}{$\begin{array}{l}\text { Characteristics } \\
\text { General hospital }\end{array}$} & \multicolumn{2}{|c|}{ Before-matching Cohort } & \multicolumn{2}{|c|}{ Matched Cohort } \\
\hline & $178(5.4)$ & 2,398 (12.3) & $119(5.2)$ & $262(11.4)$ \\
\hline $\begin{array}{l}\text { Community } \\
\text { hospitals/clinics/others }\end{array}$ & $89(2.7)$ & $3,987(20.4)$ & $63(2.7)$ & $478(20.8)$ \\
\hline \multicolumn{5}{|l|}{ Department } \\
\hline Internal medicine & $3,144(95.7)$ & $11,629(59.4)$ & $2,193(95.5)$ & $1,394(60.7)$ \\
\hline Orthopedic surgery & $128(3.9)$ & $6,280(32.1)$ & $93(4.1)$ & $708(30.8)$ \\
\hline Other & $14(0.4)$ & $1,656(8.5)$ & $10(0.4)$ & $194(8.4)$ \\
\hline \multicolumn{5}{|l|}{ Income } \\
\hline High & $926(28.2)$ & $5,767(29.5)$ & $639(27.8)$ & $570(24.8)$ \\
\hline Intermediate & $1,331(40.5)$ & $7,971(40.7)$ & $942(41.0)$ & $981(42.7)$ \\
\hline Low & $1,029(31.3)$ & $5,827(29.8)$ & $715(31.1)$ & $745(32.4)$ \\
\hline \multicolumn{5}{|c|}{$\begin{array}{l}{ }^{a} \text { Comorbidities and the Charlson comorbidity index scores were determined within one year of the } \\
\text { index date. }\end{array}$} \\
\hline \multicolumn{5}{|c|}{ bisease duration was defined as the time from the first use of nbDMARDs to the index date. } \\
\hline \multicolumn{5}{|c|}{${ }^{c}$ Drug treatments were determined from the index date to the end of follow-up. } \\
\hline \multicolumn{5}{|c|}{$\begin{array}{l}\text { dPDC was calculated as the number of days covered by prescription divided by the number of follow- } \\
\text { up days for each patient. }\end{array}$} \\
\hline \multicolumn{5}{|c|}{ Data are presented as mean \pm standard deviation or $n(\%)$. } \\
\hline \multicolumn{5}{|c|}{$\begin{array}{l}\text { TNF, tumor necrosis factor; nbDMARDs, non-biologic disease-modifying anti-rheumatic drugs; CLD, } \\
\text { chronic liver disease; CVD, cardiovascular disease; COPD, chronic obstructive pulmonary disease; PUD, } \\
\text { peptic ulcer disease; PDC, proportion of days covered; NSAIDs, non-steroidal anti-inflammatory drugs }\end{array}$} \\
\hline
\end{tabular}

The newly diagnosed cancer incidence rate per 1,000 person-years in the TNF inhibitor and nbDMARD cohorts was 6.5 and 15.0, respectively, before matching and 6.5 and 15.6 after matching. Multivariable analysis found TNF inhibitor use to be consistently associated with a low risk of cancer development (adjusted HR, 0.492; 95\% Cl, 0.351-0.688 before matching; adjusted HR, 0.379; 95\% Cl, 0.255-0.563 after matching; Table 2). Cardiovascular disease showed a negative association with cancer risk (adjusted HR, $0.867 ; 95 \% \mathrm{Cl} 0.761-0.987$ ), while higher age, male sex, presence of chronic liver disease, and high PDC by nbDMARDs, corticosteroids, and NSAIDs were associated with an increased risk of cancer development. Among these, PDC by corticosteroids was also associated with a high risk of developing cancer in the matched cohort (adjusted HR, 4.418; 95\% Cl, 1.495-13.055; Supplementary Table 1). 
Table 2

Incidence Rates and Adjusted Hazard Ratios for Cancer Development

\begin{tabular}{|c|c|c|c|c|}
\hline & \multicolumn{2}{|c|}{ Before-matching Cohort } & \multicolumn{2}{|c|}{ Matched Cohort } \\
\hline & $\begin{array}{l}\text { TNF Inhibitor } \\
\text { Cohort }\end{array}$ & $\begin{array}{l}\text { nbDMARD } \\
\text { Cohort }\end{array}$ & $\begin{array}{l}\text { TNF Inhibitor } \\
\text { Cohort }\end{array}$ & $\begin{array}{l}\text { nbDMARD } \\
\text { Cohort }\end{array}$ \\
\hline & (12,491.9 PY) & (117,735.9 PY) & (8,884.8 PY) & $(8,422.2 \mathrm{PY})$ \\
\hline Event number & 81 & 1,769 & 58 & 131 \\
\hline $\begin{array}{l}\text { IR }(1,000 \text { person- } \\
\text { years) }\end{array}$ & 6.5 & 15.0 & 6.5 & 15.6 \\
\hline aHR $(95 \% \mathrm{Cl})$ & \multicolumn{2}{|c|}{$0.492(0.351,0.688)$} & \multicolumn{2}{|c|}{$0.379(0.255,0.563)$} \\
\hline
\end{tabular}

\section{Association Between TNF Inhibitor Use and Site-Specific Cancer Development}

The multivariable Cox regression analyses on site-specific cancer in the before-matching cohort found adjusted HRs (95\% Cls) in the TNF inhibitor users were significantly lower than in the nbDMARD users for gastrointestinal (adjusted HR, 0.432; 95\% Cl, 0.235-0.797), breast (adjusted HR, 0.146; 95\% Cl, 0.0450.474 ), and genitourinary (adjusted $\mathrm{HR}, 0.220 ; 95 \% \mathrm{Cl}, 0.059-0.820$ ) cancers. No significant association was observed between TNF inhibitor use and site-specific cancer development in the matched cohort. The risk of skin cancer or hematologic malignancy was not associated with TNF inhibitor use in this study (Table 3). 
Table 3

Adjusted Hazard Ratios for Site-Specific Cancer Development

\begin{tabular}{|c|c|c|c|c|c|c|}
\hline \multirow[t]{4}{*}{ Cancer Site } & \multicolumn{4}{|c|}{ Event Number } & \multicolumn{2}{|c|}{$\operatorname{aHR}(95 \% \mathrm{Cl})$} \\
\hline & \multicolumn{2}{|c|}{ Before-matching Cohort } & \multicolumn{2}{|c|}{ Matched Cohort } & \multirow{3}{*}{$\begin{array}{l}\begin{array}{l}\text { Before- } \\
\text { matching } \\
\text { Cohort }\end{array} \\
(130,227.8 \\
\text { PY) }\end{array}$} & \multirow{3}{*}{$\begin{array}{l}\text { Matched } \\
\text { Cohort } \\
(17,307.0 \\
\text { PY) }\end{array}$} \\
\hline & $\begin{array}{l}\text { TNF } \\
\text { Inhibitor }\end{array}$ & $\begin{array}{l}\text { nbDMARD } \\
\text { Cohort }\end{array}$ & $\begin{array}{l}\text { TNF } \\
\text { Inhibitor }\end{array}$ & $\begin{array}{l}\text { nbDMARD } \\
\text { Cohort }\end{array}$ & & \\
\hline & $\begin{array}{l}(12,491.9 \\
\text { PY) }\end{array}$ & $\begin{array}{l}(117,735.9 \\
\text { PY) }\end{array}$ & $\begin{array}{l}(8,884.8 \\
\text { PY) }\end{array}$ & $\begin{array}{l}(8,422.2 \\
\text { PY) }\end{array}$ & & \\
\hline All cancer & 81 & 1,769 & 58 & 131 & $\begin{array}{l}0.492 \\
(0.351 \\
0.688)\end{array}$ & $\begin{array}{l}0.379 \\
(0.255 \\
0.563)\end{array}$ \\
\hline $\begin{array}{l}\text { Oropharyngeal } \\
\text { cavity }\end{array}$ & 0 & 14 & 0 & 1 & - & - \\
\hline Gl tract & 25 & 536 & 18 & 41 & $\begin{array}{l}0.432 \\
(0.235, \\
0.797)\end{array}$ & $\begin{array}{l}0.670 \\
(0.367 \\
1.223)\end{array}$ \\
\hline Upper GI tract & 8 & 149 & 7 & 11 & $\begin{array}{l}0.846 \\
(0.296 \\
2.421)\end{array}$ & - \\
\hline $\begin{array}{l}\text { Colon and } \\
\text { rectum }\end{array}$ & 9 & 163 & 6 & 14 & $\begin{array}{l}0.385 \\
(0.132, \\
1.124)\end{array}$ & - \\
\hline Liver & 4 & 159 & 3 & 12 & $\begin{array}{l}0.377 \\
(0.088, \\
1.616)\end{array}$ & - \\
\hline Biliary tract & 6 & 106 & 3 & 5 & $\begin{array}{l}0.372 \\
(0.096 \\
1.436)\end{array}$ & - \\
\hline $\begin{array}{l}\text { Respiratory } \\
\text { system }\end{array}$ & 19 & 308 & 13 & 13 & $\begin{array}{l}0.762 \\
(0.382, \\
1.522)\end{array}$ & $\begin{array}{l}1.371 \\
(0.458 \\
4.109)\end{array}$ \\
\hline $\begin{array}{l}\text { Bone and soft } \\
\text { tissue }\end{array}$ & 1 & 4 & 0 & 0 & $\begin{array}{l}8.366 \\
(0.325, \\
215.255)\end{array}$ & - \\
\hline Skin & 2 & 57 & 1 & 4 & $\begin{array}{l}0.159 \\
(0.014, \\
1.858)\end{array}$ & - \\
\hline
\end{tabular}

aHR, adjusted hazard ratio; $\mathrm{Cl}$, confidence interval; TNF, tumor necrosis factor; nbDMARDs, nonbiologic disease-modifying anti-rheumatic drugs; PY, person-years; GI, gastrointestinal 


\begin{tabular}{|c|c|c|c|c|c|c|}
\hline \multirow[t]{4}{*}{ Cancer Site } & \multicolumn{4}{|c|}{ Event Number } & \multicolumn{2}{|l|}{ aHR $(95 \% \mathrm{Cl})$} \\
\hline & \multicolumn{2}{|c|}{ Before-matching Cohort } & \multicolumn{2}{|c|}{ Matched Cohort } & \multirow{3}{*}{ 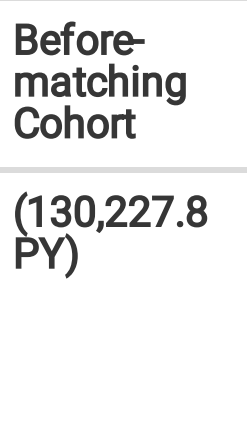 } & \multirow{3}{*}{$\begin{array}{l}\text { Matched } \\
\text { Cohort } \\
(17,307.0 \\
\text { PY) }\end{array}$} \\
\hline & $\begin{array}{l}\text { TNF } \\
\text { Inhibitor }\end{array}$ & $\begin{array}{l}\text { nbDMARD } \\
\text { Cohort }\end{array}$ & $\begin{array}{l}\text { TNF } \\
\text { Inhibitor }\end{array}$ & $\begin{array}{l}\text { nbDMARD } \\
\text { Cohort }\end{array}$ & & \\
\hline & $\begin{array}{l}(12,491.9 \\
\text { PY) }\end{array}$ & $\begin{array}{l}(117,735.9 \\
\text { PY) }\end{array}$ & $\begin{array}{l}(8,884.8 \\
\text { PY) }\end{array}$ & $\begin{array}{l}(8,422.2 \\
\text { PY })\end{array}$ & & \\
\hline Melanoma & 1 & 5 & 0 & 0 & $\begin{array}{l}0.126 \\
(0.001 \\
20.528)\end{array}$ & - \\
\hline $\begin{array}{l}\text { Non- } \\
\text { melanoma }\end{array}$ & 1 & 52 & 1 & 4 & $\begin{array}{l}0.505 \\
(0.023 \\
11.019)\end{array}$ & - \\
\hline Breast & 8 & 316 & 7 & 58 & $\begin{array}{l}0.146 \\
(0.045 \\
0.474)\end{array}$ & $\begin{array}{l}0.748 \\
(0.090, \\
6.221)\end{array}$ \\
\hline $\begin{array}{l}\text { Gynecologic } \\
\text { system }\end{array}$ & 8 & 95 & 6 & 7 & $\begin{array}{l}1.970 \\
(0.660, \\
5.883)\end{array}$ & - \\
\hline $\begin{array}{l}\text { Genitourinary } \\
\text { system }\end{array}$ & 6 & 181 & 3 & 7 & $\begin{array}{l}0.220 \\
(0.059, \\
0.820)\end{array}$ & - \\
\hline $\begin{array}{l}\text { Central } \\
\text { nervous } \\
\text { system }\end{array}$ & 0 & 12 & 0 & 1 & - & - \\
\hline $\begin{array}{l}\text { Endocrine } \\
\text { system }\end{array}$ & 9 & 164 & 8 & 31 & $\begin{array}{l}0.901(0.331, \\
2.456)\end{array}$ & $\begin{array}{l}0.518 \\
(0.078, \\
3.454)\end{array}$ \\
\hline $\begin{array}{l}\text { Hematologic } \\
\text { system }\end{array}$ & 1 & 140 & 0 & 13 & $\begin{array}{l}0.011(0, \\
1.037)\end{array}$ & - \\
\hline Lymphoma & 0 & 58 & 0 & 6 & - & - \\
\hline
\end{tabular}

\section{Subgroup and Sensitivity Analyses}

The subgroup analysis revealed that the adjusted HRs for cancer consistently tended to be lower in the TNF inhibitor cohort (Supplementary Table 2). Sensitivity analysis based on various lag times of cancer development demonstrated that the cancer risk tended to be consistently lower in the TNF inhibitor cohort (Supplementary Table 3). 


\section{The Risk of Tuberculosis Development by TNF Inhibitor Use}

The risk of tuberculosis development was confirmed to be higher in TNF inhibitor users in the matched (adjusted HR: 2.816; 95\% Cl, 1.243-6.383), but not the unmatched cohort (adjusted HR, $0.886 ; 95 \% \mathrm{Cl}$, $0.612-1.283)$.

\section{Discussion}

This is the largest study to date evaluating the risk of newly diagnosed cancer following TNF inhibitor use in Korean patients with RA. The study data included all TNF inhibitor claims in the Korean NHIS-NHID since the first TNF inhibitor was introduced to the NHIS in 2002 till 2016.

The study results indicated that the risk of cancer development was significantly lower in the TNF inhibitor cohort than the nbDMARD cohort before and after matching. This finding was consistent with several previous studies using the claims data. Wu et al. [1] and Lan et al. [14] reported adjusted HRs of $0.63(95 \% \mathrm{Cl}, 0.49-0.80)$ and $0.59(95 \% \mathrm{Cl}, 0.36-0.98)$, respectively, in the Taiwanese population. Cho et al. [13] reported an odds ratio (OR) of $0.42(95 \% \mathrm{Cl}, 0.25-0.73)$ in the Korean population. Only the study by Jung et al. reported an insignificant difference in the Korean population (incidence rates ratio, 0.913; $P$ $=0.546$ ) [36]. On the other hand, meta-analyses of randomized controlled trials demonstrated an increased or insignificant risk of cancer among patients receiving TNF inhibitors compared to those taking only nbDMARDs [15], [17]. Prospective cohort studies based on the German biologics register (Rheumatoide Arthritis: Beobachtung der Biologika-Therapie [RABBIT]) and Australian Rheumatology Association Database (ARAD) found no difference in the risk of cancer due to TNF inhibitors use [16], [18].

These conflicting findings could be primarily due to the characteristics of the different data sources. Studies using national claims data are less likely to experience loss to follow-up, and the consequent missed diagnosis, than clinical trials or prospective cohort studies. For example, a follow-up bias of up to $33 \%$ ( $95 \%$ bootstrap limits of -30 to $+152 \%$ ) has been reported by a study in which a birth cohort was compared with national administrative registries [37]. When it comes to the RA cohort, subjects treated with nbDMARDs are more likely to be lost to follow-up than those treated with TNF inhibitors since they do not need to visit the study center for nbDMARDs administration. This might have led to increased risk estimates for the TNF inhibitor cohort in previous cohort studies.

Differences in study design may have also contributed to the conflicting results. In many studies, including the study by Jung et al. [36] that had found no difference in cancer risk due to TNF inhibitor use, patients in the two cohorts were followed up from different or random time points in their disease course. For example, subjects in the nbDMARD cohort were observed from the start date of nbDMARD treatment and those in the TNF inhibitor cohort from the start date of TNF inhibitor use. In this situation, the TNF inhibitor cohort was likely to have a longer disease duration and a longer duration of nbDMARD use since clinical guidelines and reimbursement policies allow the prescription of TNF inhibitors only to those 
patients refractory to nbDMARDs. Such differences could subsequently lead to a relative increase in disease activity and complications in the TNF inhibitor cohort as the disease progresses over time. The point is that not only the presence of RA has been associated with an increased risk of cancer, but also RA disease activity [3], nbDMARDs use [5], and complications such as lung disease [4]. We could control this potential bias by matching the start year of nbDMARDs use and following up each subject in the nbDMARDs cohort from the start date of the TNF inhibitor use by the matched pair (Figure 2). This also enabled us to control the possible bias from changes in the clinical environment over time. Several new TNF inhibitors were developed during the study period, and clinical experience accumulated; therefore, biologic DMARD use has increased globally [38]. Clinical guidelines were amended many times as well. Unless controlled for, these changes over time might affect patient selection and the outcomes.

The anti-inflammatory effects of TNF inhibitors have been suggested to play a role in reducing cancer risk since chronic inflammation has been implicated in the pathogenesis of cancer [39]. TNF inhibitors were found to suppress tumor progression by disrupting TNF-a-related tumor-promoting inflammatory signaling in vitro and in vivo [40-42]. Another class of anti-inflammatory drugs, NSAIDs, has also been reported to be associated with a decreased risk of cancer, especially breast, colorectal, and genitourinary cancers [43-48]. Coincidentally, the risk of these three cancer types was shown to be significantly reduced for patients treated with TNF inhibitors in the secondary endpoint analysis of this study. It might be theoretically logical to expect that drugs exerting anti-inflammatory effects such as NSAIDs and TNF inhibitors would reduce the cancer risk by controlling chronic inflammation. However, a cautious interpretation is needed because the inference that drugs with anti-inflammatory effects would also be cancer-protective is a risky oversimplification. The exact mechanism and extent of association between cancer risk and anti-rheumatic drugs remains unclear and needs to be further researched.

Lastly, the ongoing issues surrounding cancer risk and TNF inhibitors may have shaped the behavior of physicians. For example, physicians might have avoided prescribing TNF inhibitors to patients clinically judged to be at high risk for cancer, thereby affecting the risk of cancer in TNF inhibitor users.

The multivariable analysis showed that cancer occurrence in the cohort before matching was positively associated with increasing age, male sex, presence of chronic liver disease, and high PDC by nbDMARDs, corticosteroids, and NSAIDs. Age, sex, and chronic liver disease were established as carcinogenetic risk factors [49]. The high PDC by anti-rheumatic drugs might indicate a high RA disease activity, which is already known as an accelerating factor of cancer development [50]. Among the anti-rheumatic drugs mentioned above, increased use of corticosteroids remained a significant risk factor for cancer in the matched cohort. This finding is consistent with the result of a previous study on the influence of corticosteroids on the risk of skin cancer in patients with RA (adjusted OR, 2.96; 95\% Cl, 1.67-5.22 for cumulative doses of corticosteroids greater than $10 \mathrm{~g}$ ) [51]. Patients with cardiovascular disease in our study were less likely to develop cancer. Similarly, Wu et al. reported a negative association between ischemic heart disease and cancer in patients with $\mathrm{RA}$ (adjusted $\mathrm{HR}, 0.70 ; 95 \% \mathrm{Cl}, 0.54-0.92$ ) [1]. Those authors mentioned an independent association between cancer and the use of medications for ischemic heart disease, including NSAIDs, making this link worth further investigation.

Page 13/21 
This study has several limitations. Like many other studies using claims data, variables such as family history, smoking and alcohol use, body mass index, and laboratory data, especially on disease activity, were unavailable. However, we adjusted for the use of anti-rheumatic drugs as surrogate markers of disease activity. Secondly, the sample size of the matched cohort was not large enough to estimate the risk of site-specific cancer. Lastly, we could not obtain data on the use of drugs not covered by the NHIS. Therefore, our results may have been confounded by uninsured use of TNF inhibitors by private procurement or clinical trial participation. Data linkage between claims and clinical data is needed to overcome these shortcomings of our study.

On the other hand, this study has several strengths compared to previous studies. We used nationwide administrative data for the longest period the NHIS-NHID could provide. Since Korea offers a universal health insurance service, we were able to enlarge the sample size, minimize selection bias, obtain 15 years of data, and thus enhance the statistical power to detect rare cancer events using this data source. It also permitted a solid study design. We could include only RA incident cases, account for the time of TNF inhibitor use, and match the start year of nbDMARD use, which was impossible in previous studies due to the small sample size and short study periods. Lastly, we confirmed the validity of this study by showing the increased risk of tuberculosis in the matched TNF inhibitor cohort. The lack of significance before matching is thought to be due to the relatively large number of patients enrolled in the nbDMARD cohort in the early study period, when the diagnostic method for tuberculosis was less established [35].

\section{Conclusions}

In conclusion, we have demonstrated that TNF inhibitor use was not associated with an increased risk of cancer development, and rather associated with a decreased incidence of cancer in Korean patients with RA. This finding is consistent with previous epidemiologic studies. Further studies linking claims and clinical data are needed to confirm our results.

\section{Abbreviations}

RA

Rheumatoid arthritis

nbDMARDs

non-biologic disease-modifying anti-rheumatic drugs

TNF

tumor necrosis factor

NHIS-NHID

National Health Insurance Service-National Health Information Database

ICD-10

International Classification of Diseases-10

PDC

proportion of days covered

Page 14/21 
NSAIDS

nonsteroidal anti-inflammatory drugs

HRs

hazard ratios

Cls

confidence intervals

OR

odds ratio.

\section{Declarations}

\section{Ethics approval and consent to participate}

This study was approved by the institutional review board of the Seoul National University Hospital (No. 1710-112-897).

\section{Consent for publication}

Not applicable.

\section{Availability of data and materials}

The computing code required to replicate the results is provided on request. We cannot provide data of the NHIS-NHID due to data user agreement but the data could be requested from the NHIS-NHID.

\section{Competing interests}

There is no conflict of interest.

\section{Funding}

This research was supported by a grant of the Korea Health Technology R\&D Project through the Korea Health Industry Development Institute (KHIDI), funded by the Ministry of Health \& Welfare, Republic of Korea (grant number: HC17C0069).

\section{Authors' contributions}

Boyoon Choi: Conceptualization, Formal analysis, Investigation, Methodology, Writing - Original draft preparation. Hyun Jin Park: Data curation, Formal analysis, Validation. Yun-Kyoung Song:

Conceptualization, Methodology, Funding acquisition. Yoon-Jeong Oh: Conceptualization, Investigation, Methodology. In-Wha Kim: Methodology, Supervision, Writing - Review \& editing. Jung Mi Oh: Conceptualization, Funding acquisition, Supervision, Writing - Review \& editing.

\section{Acknowledgements}


Not applicable.

\section{References}

1. Wu C-Y, Chen D-Y, Shen J-L, Ho HJ, Chen C-C, Kuo KN, et al. The risk of cancer in patients with rheumatoid arthritis taking tumor necrosis factor antagonists: a nationwide cohort study. Arthritis Res Ther. 2014;16:1-12.

2. Love T, Solomon DH. The relationship between cancer and rheumatoid arthritis: still a large research agenda [Editorial]. Arthritis Res Ther. 2008;10:109.

3. Baecklund E, Iliadou A, Askling J, Ekbom A, Backlin C, Granath F, et al. Association of chronic inflammation, not its treatment, with increased lymphoma risk in rheumatoid arthritis. Arthritis Rheum. 2006;54:692-701.

4. Pundole X, Suarez-Almazor ME. Cancer and Rheumatoid Arthritis. Rheum Dis Clin North Am. 2020;46:445-62.

5. Georgescu L, Quinn GC, Schwartzman S, Paget SA. Lymphoma in patients with rheumatoid arthritis: Association with the disease state or methotrexate treatment with the disease state or methotrexate treatment. Semin Arthritis Rheum. 1997;26:794-804.

6. Nam JL, Takase-Minegishi K, Ramiro S, Chatzidionysiou K, Smolen JS, Van Der Heijde D, et al. Efficacy of biological disease-modifying antirheumatic drugs: a systematic literature review informing the 2016 update of the EULAR recommendations for the management of rheumatoid arthritis. Ann Rheum Dis. 2017;76:1113-36.

7. Aggarwal BB, Shishodia S, Sandur SK, Pandey MK, Sethi G. Inflammation and cancer: how hot is the link? Biochem Pharmacol. 2006;72:1605-21.

8. Goh FG, Midwood KS. Intrinsic danger: activation of Toll-like receptors in rheumatoid arthritis. Rheumatology. 2012;51:7-23.

9. Baecklund E, Smedby KE, Sutton L-A, Askling J, Rosenquist R. Lymphoma development in patients with autoimmune and inflammatory disorders-what are the driving forces? Semin Cancer Biol. 2014;24:61-70.

10. Nakane A, Minagawa T, Kato K. Endogenous tumor necrosis factor (cachectin) is essential to host resistance against Listeria monocytogenes infection. Infect Immun. 1988;56:2563-9.

11. Mastroeni P, Villarreal-Ramos B, Hormaeche C. Effect of late administration of anti-TNa antibodies on a Salmonella infection in the mouse model. Microb Pathog. 1993;14:473-80.

12. Balkwill F. Tumor necrosis factor or tumor promoting factor? Cytokine Growth Factor Rev. 2002;13:135-41.

13. Cho S-K, Lee J, Han M, Bae S-C, Sung Y-K. The risk of malignancy and its incidence in early rheumatoid arthritis patients treated with biologic DMARDs. Arthritis Res Ther. 2017;19:277.

14. Lan J-L, Tseng C-H, Chen J-H, Cheng C-F, Liang W-M, Tsay GJ. Reduced risk of all-cancer and solid cancer in Taiwanese patients with rheumatoid arthritis treated with etanercept, a TNF-a inhibitor. Med 
(Baltim). 2017;96:e6055.

15. Bongartz T, Sutton AJ, Sweeting MJ, Buchan I, Matteson EL, Montori V. Anti-TNF antibody therapy in rheumatoid arthritis and the risk of serious infections and malignancies: systematic review and meta-analysis of rare harmful effects in randomized controlled trials. JAMA. 2006;295:2275-85.

16. Buchbinder R, Van Doornum S, Staples M, Lassere M, March L. Malignancy risk in Australian rheumatoid arthritis patients treated with anti-tumour necrosis factor therapy: analysis of the Australian Rheumatology Association Database (ARAD) prospective cohort study. BMC Musculoskelet Disord. 2015;16:309.

17. Lopez-Olivo MA, Tayar JH, Martinez-Lopez JA, Pollono EN, Cueto JP, Gonzales-Crespo MR, et al. Risk of malignancies in patients with rheumatoid arthritis treated with biologic therapy: a meta-analysis. JAMA. 2012;308:898-908.

18. Strangfeld A, Hierse F, Rau R, Burmester G-R, Krummel-Lorenz B, Demary W, et al. Risk of incident or recurrent malignancies among patients with rheumatoid arthritis exposed to biologic therapy in the German biologics register RABBIT. Arthritis Res Ther. 2010;12:R5.

19. Raaschou P, Simard JF, Hagelberg CA, Askling J, ARTIS Study Group. Rheumatoid arthritis, antitumour necrosis factor treatment, and risk of squamous cell and basal cell skin cancer: cohort study based on nationwide prospectively recorded data from Sweden. BMJ. 2016;352:i262.

20. Mariette X, Tubach F, Bagheri H, Bardet M, Berthelot JM, Gaudin P, et al. Lymphoma in patients treated with anti-TNF: results of the 3-year prospective French RATIO registry. Ann Rheum Dis. 2010;69:400-8.

21. Mercer LK, Askling J, Raaschou P, Dixon WG, Dreyer L, Hetland ML, et al. Risk of invasive melanoma in patients with rheumatoid arthritis treated with biologics: results from a collaborative project of 11 European biologic registers. Ann Rheum Dis. 2017;76:386-91.

22. Mercer LK, Galloway JB, Lunt M, Davies R, Low AL, Dixon WG, et al. Risk of lymphoma in patients exposed to antitumour necrosis factor therapy: results from the British Society for Rheumatology Biologics Register for Rheumatoid Arthritis. Ann Rheum Dis. 2017;76:497-503.

23. Cheol Seong S, Kim Y-Y, Khang Y-H, Heon Park J, Kang H-J, Lee H, et al. Data resource profile: the national health information database of the National Health Insurance Service in South Korea. Int $J$ Epidemiol. 2017;46:799-800.

24. Song YJ. The South Korean health care system. Jpn Med Assoc J. 2009;52:206-9.

25. Cho S-K, Sung Y-K, Choi C-B, Kwon J-M, Lee E-K, Bae S-C. Development of an algorithm for identifying rheumatoid arthritis in the Korean National Health Insurance claims database. Rheumatol Int. 2013;33:2985-92.

26. Aletaha D, Neogi T, Silman AJ, Funovits J, Felson DT, Bingham CO III, et al. 2010 Rheumatoid Arthritis Classification Criteria. Arthritis Rheum. 2010;62:2569-81.

27. Seo HJ, Oh I-H, Yoon S-J. A comparison of the cancer incidence rates between the national cancer registry and insurance claims data in Korea. Asian Pac J Cancer Prev. 2012;13:6163-8. 
28. Charlson ME, Pompei P, Ales KL, MacKenzie CR. A new method of classifying prognostic comorbidity in longitudinal studies: development and validation. J Chronic Dis. 1987;40:373-83.

29. Kim Y-H, Cho K-H, Kim KH, Ryu EJ, Han KD, Kim J-S. Predicting hypertension among Korean cancer survivors: a nationwide population-based study. Eur J Cancer Care (Engl). 2018;27:e12803.

30. Stepanova M, Rafiq N, Younossi ZM. Components of metabolic syndrome are independent predictors of mortality in patients with chronic liver disease: a population-based study. Gut. 2010;59:1410-5.

31. Cho J, Choi YJ, Suh M, Sohn J, Kim H, Cho SK, et al. Air pollution as a risk factor for depressive episode in patients with cardiovascular disease, diabetes mellitus, or asthma. J Affect Disord. 2014;157:45-51.

32. Kim J, Rhee CK, Yoo KH, Kim YS, Lee SW, Park YB, et al. The health care burden of high grade chronic obstructive pulmonary disease in Korea: analysis of the Korean Health Insurance Review and Assessment Service data. Int J Chron Obstruct Pulmon Dis. 2013;8:561-8.

33. Lee JW, Kim HK, Woo YS, Jahng J, Jin YR, Park JH, et al. Optimal operational definition of patient with peptic ulcer bleeding for big data analysis using combination of clinical characteristics in a secondary general hospital. Korean J Gastroenterol. 2016;68:77-86. [Article in Korean].

34. Singh JA, Furst DE, Bharat A, Curtis JR, Kavanaugh AF, Kremer JM, et al. 2012 update of the 2008 American College of Rheumatology recommendations for the use of disease-modifying antirheumatic drugs and biologic agents in the treatment of rheumatoid arthritis. Arthritis Care Res (Hoboken). 2012;64:625-39.

35. Park I-S, Kim Y-M, Choi Y-H, Kim S-S, Kim E-J, Won S-Y, et al. Development of advanced TB case classification model using NHI claims data. J Digit Converg. 2013;11:289-99. [Article in Korean].

36. Jung SM, Kwok S-K, Ju JH, Park Y-B, Park S-H. Risk of malignancy in patients with rheumatoid arthritis after anti-tumor necrosis factor therapy: results from Korean National Health Insurance claims data. Korean J Intern Med. 2019;34:669-77.

37. Greene N, Greenland S, Olsen J, Nohr EA. Estimating bias from loss to follow-up in the Danish National Birth Cohort. Epidemiology. 2011;22:815-22.

38. Desai RJ, Solomon DH, Jin Y, Liu J, Kim SC. Temporal trends in use of biologic DMARDs for rheumatoid arthritis in the United States: a cohort study of publicly and privately insured patients. J Manag Care Spec Pharm. 2017;23:809-14.

39. Guillem EB, Sampsel JW. Immune-promoted tumor cell invasion and metastasis. New considerations in cancer therapy. Adv Exp Med Biol. 2003;532:153-73.

40. Egberts J-H, Cloosters V, Noack A, Schniewind B, Thon L, Klose S, et al. Anti-tumor necrosis factor therapy inhibits pancreatic tumor growth and metastasis. Cancer Res. 2008;68:1443-50.

41. Guillem EB, Sampsel JW. Antitumor-associated antigens IgGs: dual positive and negative potential effects for cancer therapy. Adv Exp Med Biol. 2006;587:341-74.

42. Hamaguchi T, Wakabayashi H, Matsumine A, Sudo A, Uchida A. TNF inhibitor suppresses bone metastasis in a breast cancer cell line. Biochem Biophys Res Commun. 2011;407:525-30. 
43. Cibere J, Sibley J, Haga M. Rheumatoid arthritis and the risk of malignancy. Arthritis Rheum. 1997;40:1580-6.

44. Mellemkjaer L, Linet MS, Gridley G, Frisch M, Møller G, Olsen JH. Rheumatoid arthritis and cancer risk. Eur J Cancer. 1996;32A:1753-7.

45. Simon TA, Thompson A, Gandhi KK, Hochberg MC, Suissa S. Incidence of malignancy in adult patients with rheumatoid arthritis: a meta-analysis. Arthritis Res Ther. 2015;17:212.

46. Thomas E, Brewster DH, Black RJ, Macfarlane GJ. Risk of malignancy among patients with rheumatic conditions. Int J Cancer. 2000;88:497-502.

47. Smitten AL, Simon TA, Hochberg MC, Suissa S. A meta-analysis of the incidence of malignancy in adult patients with rheumatoid arthritis. Arthritis Res Ther. 2008;10:R45.

48. Vidal AC, Howard LE, Moreira DM, Castro-Santamaria R, Andriole GL, Freedland SJ. Aspirin, NSAIDs, and risk of prostate cancer: results from the REDUCE study. Clin Cancer Res. 2015;21:756-62.

49. Charvat $H$, Sasazuki S, Inoue M, Iwasaki M, Sawada N, Shimazu T, et al. Impact of five modifiable lifestyle habits on the probability of cancer occurrence in a Japanese population-based cohort: results from the JPHC study. Prev Med. 2013;57:685-9.

50. Abásolo L, Júdez E, Descalzo MA, González-Álvaro I, Jover JA, Carmona L, et al. Cancer in rheumatoid arthritis: occurrence, mortality, and associated factors in a South European population. Semin Arthritis Rheum. 2008;37:388-97.

51. Tseng H-W, Lu L-Y, Lam H-C, Tsai K-W, Huang W-C, Shiue Y-L. The influence of disease-modifying anti-rheumatic drugs and corticosteroids on the association between rheumatoid arthritis and skin cancer: a nationwide retrospective case-control study in Taiwan. Clin Exp Rheumatol. 2018;36:4718.

\section{Figures}




\section{2,419 RA patients identified from the Korean NHIS-NHID}

\section{9,568 excluded}

8,853 due to Medicaid Aid benefits

22,745 due to RA treatment history in screening period

1,388 due to cancer history in screening period

532 due to age under 19 years old

2,351 due to use of non-TNF biologics

3,699 due to RA treatment for less than six months or poor compliance of TNF inhibitors

\section{Before-matching cohort}

\section{2,851 eligible RA patients}

3,286 patients treated with TNF inhibitors 19,565 patients treated only with nbDMARDs

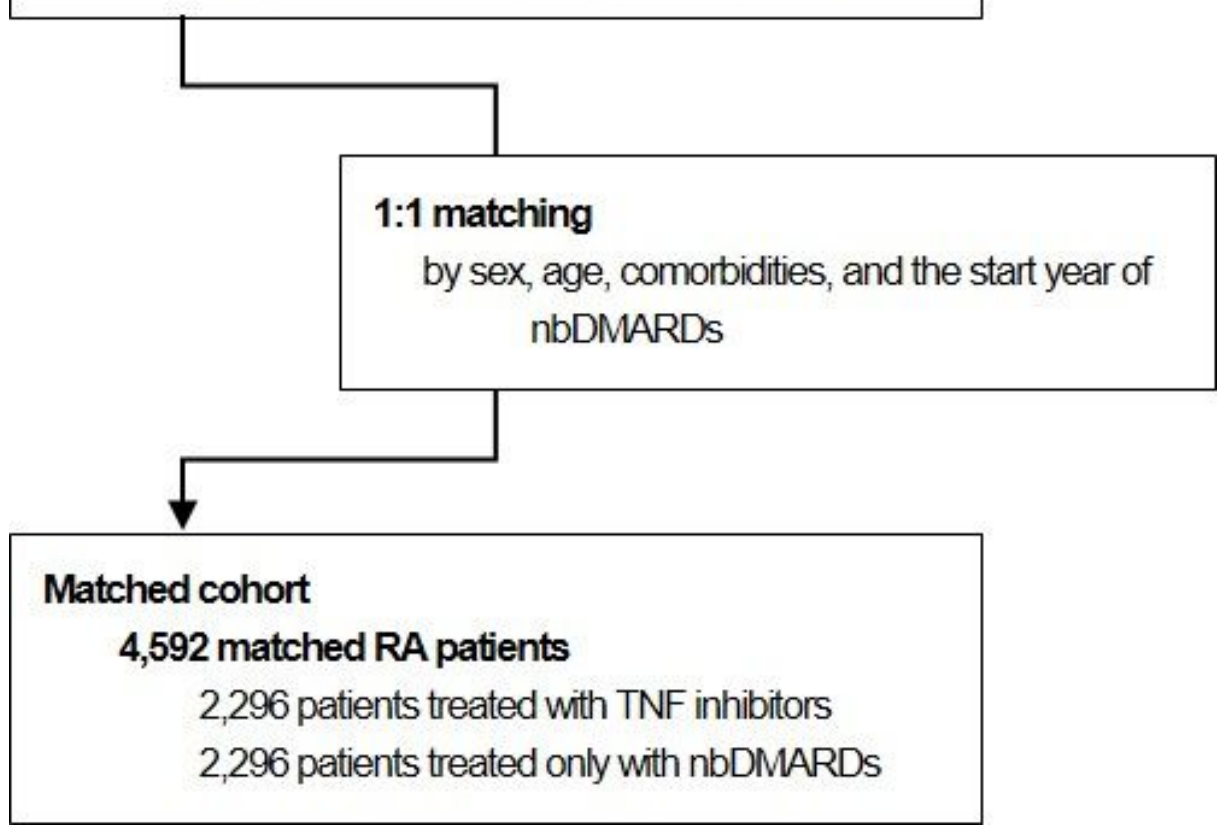

Figure 1

Flow Diagram of Study Subject Selection 


\section{Timeline}
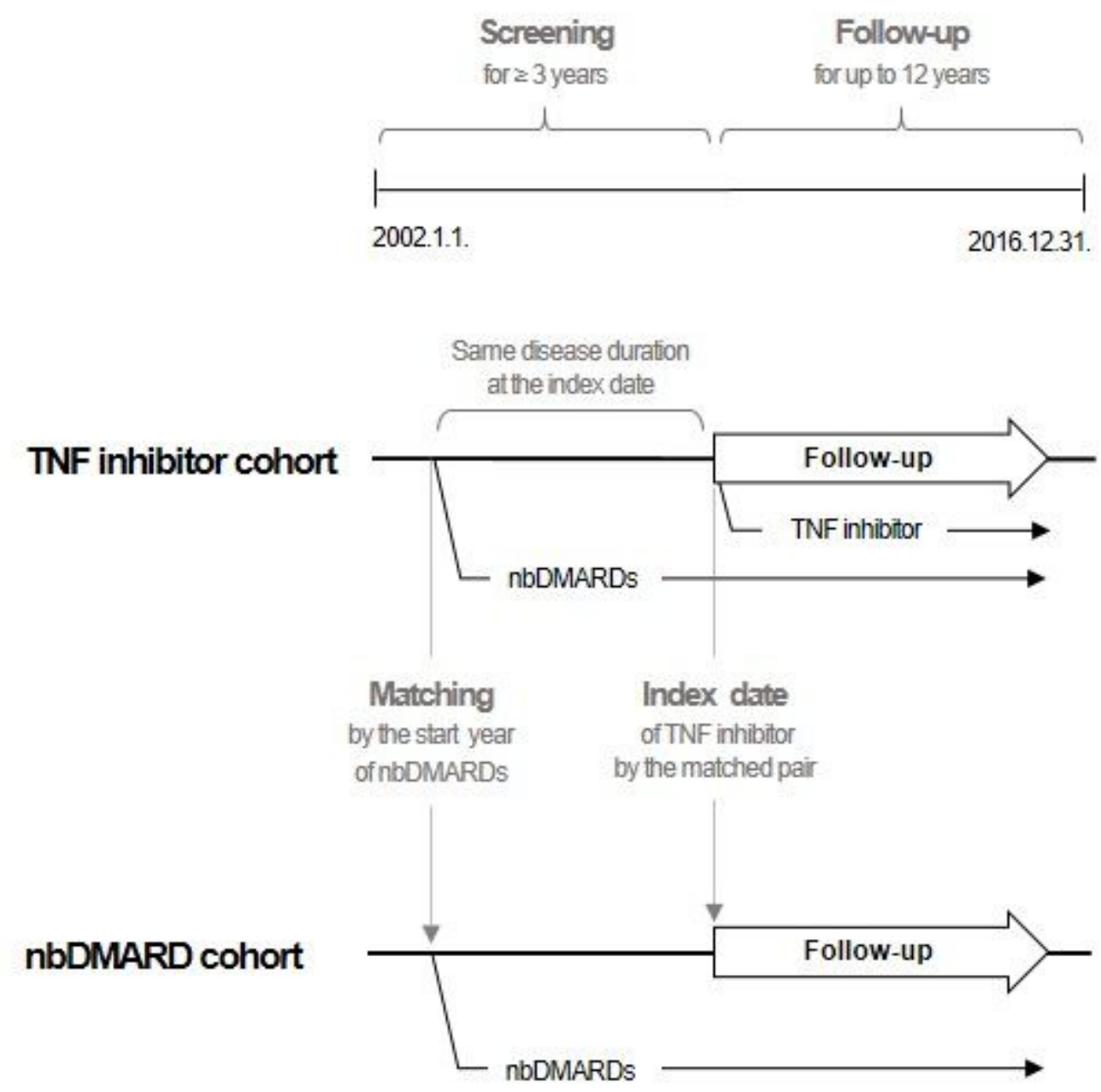

Figure 2

Screening and Follow-up Time Points in Each Cohort

\section{Supplementary Files}

This is a list of supplementary files associated with this preprint. Click to download.

- Supplementarymaterials.docx 